\title{
Percepção da Paisagem: Aerogeradores em Tapes (RS) ${ }^{i}$ Landscape Perception: the Wind turbines in Tapes (RS)
}

\author{
Lucile Lopes Bierii \\ Universidade Federal do Rio Grande do Sul \\ Porto Alegre, Brasil \\ Roberto Verdum iii \\ Universidade Federal do Rio Grande do Sul \\ Porto Alegre, Brasil
}

\begin{abstract}
Resumo: A transformação da paisagem por meio de empreendimentos eólicos é um fenômeno relativamente novo no Rio Grande do Sul e no Brasil. Contudo, a matriz energética brasileira está em expansão, principalmente a geração eólica. Embora esse tipo de energia seja considerado de baixo impacto ambiental, constata-se que cresce a preocupação de alguns segmentos da sociedade em relação aos impactos que podem ocorrer no meio ambiente e nas pessoas. Entre eles está a intrusão visual decorrida da inserção dos aerogeradores, ou o impacto sobre a paisagem. O objetivo desse artigo é mostrar o levantamento sobre a percepção da paisagem em relação à possibilidade da implantação de empreendimentos de energia eólica no município de Tapes/RS. Na tentativa de contemplar o objetivo proposto, no estudo utiliza-se a categoria de análise da paisagem por meio do método da percepção. Em busca dos aspectos objetivos e subjetivos que norteiam a opinião da população perante um empreendimento hipotético, observa-se que há uma série de elementos envolvidos nesse processo que ultrapassa a simples aceitação do empreendimento. Contudo, os resultados refletem o grande apelo econômico que os aerogeradores representam para a população local.
\end{abstract}

Palavras-chave: Paisagem; Aerogeradores; Impactos Ambientais; Tapes; Rio Grande do Sul.

\begin{abstract}
The transformation of the landscape through wind farms is a relatively new phenomenon in Rio Grande do Sul and Brazil. However, the Brazilian energy matrix is expanding, especially in wind generation. Although this type of energy is considered low environmental impact, it appears that the growing concern of some segments of society in relation to the impacts that may occur in the environment. Among them is the visual intrusion of wind turbines elapsed insertion, or the impact on the landscape. The aim of this paper is to show the survey on the perception of the landscape in relation to the possibility of implementing wind power projects in the municipality of Tapes / RS. In an attempt to consider the proposed goal, the study uses the category of landscape analysis,
\end{abstract}

\footnotetext{
' Este artigo é uma síntese da revisão do Trabalho de Conclusão de Curso "Estudo da Paisagem: implantação de aerogeradores em Tapes/RS" (BIER, 2013), do Bacharelado em Geografia pela Universidade Federal do Rio Grande do Sul.

ii Geógrafa e Mestranda do PPG em Geografia - IGEO da UFRGS.

iii Professor Doutor do Departamento de Geografia, PPG em Geografia/IGEO e PGDR/FCE/UFRGS. verdum@ufrgs.br
} 
Bier, L. L. e Verdum, R.

by the method of perception. In pursuit of the objective and subjective aspects that guide the opinion of the population before a hypothetical enterprise, it is observed that there are a number of elements involved in this process beyond the mere acceptance of the project. However, the results reflect the great economic appeal that the turbines pose to the local population.

Keywords: Landscape; Wind Turbines; Environmental Impacts: Tapes; Rio Grande do Sul.

\section{Introdução}

O estudo da paisagem permite ao geógrafo entender que a relação da sociedade com a natureza seja compreendida na complexidade que lhe é inerente. A paisagem é, ao mesmo tempo, o produto e a matriz produtiva das transformações da sociedade e, por esse motivo, de certa forma o seu reflexo. Assim, nesta pesquisa se objetiva trabalhar com a categoria de análise da paisagem, enquanto instrumento da percepção, na possibilidade da instalação de aerogeradores no município de Tapes/RS.

O município de Tapes, localizado na parte interna da planície costeira do Rio Grande do Sul, é um dos possíveis lugares para a implantação de empreendimentos eólicos, conforme vem sendo noticiado na mídia. ${ }^{1}$ Um empreendimento de energia eólica traz mudanças significativas para o município no qual é instalado. Além das melhorias em infraestrutura, em energia e estradas de acesso ao local, há a geração de impostos que devem ser convertidos em benefício da população. Contudo, a instalação dos aerogeradores modifica a paisagem na qual eles são inseridos. Os modernos equipamentos possuem dimensão entre 90 e 120 m, o que possibilita que estes podem ser avistados a quilômetros de distância, principalmente se a área tiver topografia plana, que é a característica morfológica desse município.

Embora seja uma fonte renovável de energia e de baixo impacto ambiental, se comparada com as principais formas de geração de energia, a produção por meio do vento também gera impactos de diversas ordens, o que vem motivando uma série de estudos e contestações em relação a alguns empreendimentos no exterior e no território brasileiro, inclusive pela descaracterização da paisagem.

No Rio Grande do Sul, um empreendimento de energia eólica projetado em uma área de dunas, no município de Cidreira, teve a licença ambiental cassada, devido a uma ação do Ministério Público ajuizada pela ONG Curicaca. Em nota no site da ONG, ${ }^{2}$ ela justifica a medida, por causa da extrema importância ambiental da área, na qual o ecossistema encontra-se preservado. Também, há o argumento em relação ao histórico do lugar, como sendo uma área de lazer da sociedade gaúcha, onde as famílias mantêm atividades recreativas.

Entretanto, há empreendimentos que são vistos como bem-sucedidos, como o Parque Eólico de Osório/RS, que está localizado em uma área que já era modificada pelas atividades agropecuárias. Nesse caso, a energia eólica passou a ser um complemento das atividades agropecuárias locais, inclusive símbolo da gestão pública municipal e que se agrega como atrativo turístico ao município.

O setor energético brasileiro está em franca expansão, e a fonte de energia que apresentou maior crescimento nos últimos anos foi a eólica. Estimativas apontam que essa 
tendência prosseguirá nos próximos anos, principalmente nos estados do nordeste e do sul do Brasil, por causa do seu grande potencial eólico.

Dentro desse contexto é que se insere o presente estudo, e para entender os anseios e as expectativas da população local, a percepção da paisagem permitiu entender as motivações dos entrevistados na grande aceitação do projeto, assim como as suas limitações.

\section{Energia Eólica}

A energia eólica é uma forma de energia cinética produzida pelo aquecimento diferenciado das camadas de ar, gerando uma variação de massa específica e gradientes de pressão (CE EÓLICA - PUCRS). Já o aproveitamento, ou a geração de energia eólica, ocorre pelo contato do vento com as pás do aerogerador (catavento), que ao girar dão origem à energia mecânica, a qual aciona o rotor do equipamento, gerando eletricidade (ANEEL, 2008).

A instalação de uma usina eólica depende, entre outros, do potencial eólico da região a ser instalada. Dessa forma, os dados relativos ao comportamento do vento, tais como intensidade e direção, devem ser analisados, assim como os fatores que influenciam o regime de ventos local, como: o relevo, a rugosidade do solo e outros obstáculos distribuídos ao longo da região (MME/EPE, 2007). No Brasil, apenas em 1992 a primeira turbina eólica (de $23 \mathrm{~m}$ de altura) foi instalada no Arquipélago Fernando de Noronha (ANEEL, 2005). Posteriormente, projetos de pequeno porte foram sendo implementados no país.

Entre os fatores que contribuíram para a expansão tardia da energia eólica no Brasil está a dependência da importação de equipamentos para a montagem, assim como a restrição por parte do governo na participação de empresas estrangeiras no PROINFA (Programa de Incentivo às Fontes Alternativas de Energia Elétrica). ${ }^{3}$

O PROINFA possibilitou a implementação de empreendimentos eólicos de grande porte. Instituído pela Lei no 10.438, de 26 de abril de 2002 e regulamentado pelo Decreto no 5.025, de março de 2004, tem como principal objetivo a diversificação da matriz energética por meio das fontes eólicas, de biomassa e das pequenas centrais hidrelétricas (PCHs). O programa garantiu o pagamento diferenciado por energia produzida, assim como adotou um sistema de cotas para cada tipo de tecnologia, além de subsídios por meio de linhas de crédito do Banco Nacional de Desenvolvimento - BNDES (MMA).

Em 2006, o Parque Eólico de Osório/RS, um dos projetos contemplados pelo PROINFA, entrou em operação. Contudo, os demais projetos não apresentavam competitividade nos leilões de energia em relação às outras fontes. Mas em 2009 realizou-se um leilão específico para o setor, que passou a reagir na ampliação das demandas de licenciamento.

O sistema de leilões tem sido realizado para energias renováveis desde 2007. Os resultados desse sistema, inicialmente, deixaram a desejar em relação à quantidade de capacidade instalada ao sistema elétrico nacional, mas passaram a mostrar números convincentes a partir de 2009, quando foi realizado o primeiro leilão exclusivo de 
Bier, L. L. e Verdum, R.

energia eólica. No ano seguinte, em 2010, as fontes renováveis passaram a competir mutuamente em leilões, e em 2011 termelétricas a gás natural também foram incluídas entre projetos competidores (BAITELO, 2012).

No leilão de energia previsto para o dia 12 de setembro de 2014, dos 1.041 projetos inscritos para concorrer ao certame, 708 são de geração eólica. Desses, 136 localizam-se no Rio Grande do Sul, ficando apenas atrás da Bahia, com 255 e do Rio Grande do Norte, com 139 projetos. $^{4}$

Atualmente, no Rio Grande do Sul há 21 empreendimentos de energia eólica em operação, outros 21 em construção e 17 outorgados - que não iniciaram a construção (ANEEL 2014). Considerando esses projetos existentes, iniciados ou não, e a quantidade de empreendimentos que concorreram ao leilão, pode-se prever que nos próximos anos haverá um aumento considerável de aerogeradores nas paisagens do Rio Grande do Sul. Nesse sentido, o estado já vem se preparando, visto que para o ano de 2014 está prevista a publicação de um zoneamento ambiental para implantação de parques eólicos no RS. ${ }^{5} \mathrm{O}$ documento deverá definir diretrizes para o licenciamento nas áreas potenciais do estado.

De acordo com MME/EPE (2007), entre os benefícios associados à energia eólica estão:

- $\quad$ a produção de energia elétrica a partir de uma fonte renovável;

- $\quad$ a energia gerada não emite poluentes atmosféricos e não consome combustível;

- a área das usinas pode ser utilizada para outros fins, como o uso agrícola;

- a energia eólica está entre os sistemas de produção de energia elétrica mais seguros;

- o baixo impacto ambiental;

- $\quad$ o prazo curto de instalação;

- a criação de postos de trabalho;

- ela contribui para desenvolvimento socioeconômico, permitindo acesso à energia elétrica de comunidades isoladas do sistema elétrico interligado.

Especificamente, em relação aos empregos, cabe a ressalva de que ocorrem em diferentes fases e escalas. A principal necessidade de mão de obra ocorre durante a fase de instalação ou descomissionamento do empreendimento e, por essa razão, tem caráter temporário. Durante a maior parte do tempo, ou seja, na operação e manutenção, a geração de empregos é baixa (SIMAS, 2012).

Outro aspecto a se considerar é o nível de especialização, pois é um dos fatores que podem ser decisivos para a contratação de pessoal local, podendo ser solucionado com políticas de capacitação da população. Em entrevistas realizadas com as empresas da construção civil, Simas (2012) alega que a maior parte dos empregos locais é destinada a serventes, auxiliares e ajudantes, por causa da falta de qualificação.

Dos impactos ambientais, a intrusão visual causada pelos aerogeradores é apontada como um dos principais, visto que a grande estrutura dos equipamentos pode fazer com que o caráter rural de uma região seja significativamente alterado pela sua presença (MME/EPE, 2007). Entretanto, o impacto visual de um parque eólico tem caráter subjetivo (MME/EPE, 2007; MMA). 
Dentre as diferenças de percepção destes empreendimentos, a turbina eólica pode ser vista como um símbolo de energia limpa e bem-vinda, ou, negativamente, como uma alteração de paisagem. A forma de percepção das comunidades afetadas visualmente pelos parques eólicos também depende da relação que essas populações têm com os diversos elementos que compõem a natureza. Acrescenta-se que os benefícios econômicos gerados pela implantação das fazendas eólicas, muitas vezes, são cruciais para amenizar potenciais atitudes ou percepções negativas em relação à tecnologia (EWEA, 2004 apud MMA).

O Ministério do Meio Ambiente afirma que a reação visual das pessoas deve ser levada em consideração, visto que o aumento do rendimento das turbinas eólicas vem acompanhado pelo aumento das suas dimensões. Entretanto, o impacto na paisagem depende de diversos fatores: a dimensão física, a quantidade e o desenho das turbinas, o layout (a disposição dos equipamentos) do parque e sua visibilidade, as características da paisagem, da população e seus visitantes e, sobretudo, da atitude das pessoas afetadas (MME/EPE, 2007).

Ademais, há que considerar a escala entre observadores e equipamentos, evitando uma superposição visual dos elementos ou o excesso de obstrução do campo visual que impeça a leitura do perfil original longitudinal do terreno. Também podem ser identificados impactos associados ao reflexo do sol nas pás, o que gera alternância entre luz e sombra devido ao seu movimento (MME/EPE, 2007).

Sobre a interferência das usinas nas atividades da comunidade, Simas (2012, p. 161) afirma "em muitos casos pode ter um efeito benéfico, no caso de comunidades voltadas à agricultura e pecuária, devido à diversificação de renda e possibilidade de investimento em aumento da produção". Como exemplo, podemos citar o Parque Eólico de Osório/RS.

No entanto, há casos de implantação indevida de parques eólicos em áreas de proteção ambiental, dunas ou sítios arqueológicos. Além disso, problemas relacionados ao uso do território têm ocorrido. No Ceará, há questionamento por parte dos proprietários de terra sobre os valores recebidos e o processo de desapropriação. No Rio Grande do Norte, verificam-se ações de especulação imobiliária (BAITELO, 2012).

Em um parecer técnico solicitado pelo Ministério Público Federal no Ceará, o professor do Departamento de Geografia da Universidade Federal do Ceará, Antonio Jeovah Meireles, apontou diversos impactos ambientais em um parque instalado sobre as dunas, entre eles os relacionados aos atrativos naturais:

A disposição dos aerogeradores, rede de vias de acesso, tráfego de veículos (tratores e caminhões) para a manutenção e monitoramento dos aerogeradores e terraplenagem de áreas associadas à remobilização das areias dentro da área de influência direta, irão promover alteração contínuas nos recursos naturais para o suporte dos investimentos que levam em conta a beleza e qualidade da paisagem natural imposta pela complexidade das dunas (MEIRELES, 2008, p. 36).

Nesse sentido, Simas (2012, p. 161) complementa: "Alguns parques eólicos no Nordeste são instalados em cima das dunas que servem como atrativos turísticos para a 
Bier, L. L. e Verdum, R.

comunidade, podendo impactar negativamente na fonte de renda e na atividade econômica das comunidades afetadas". Se por um lado a paisagem modificada pelos parques eólicos traz a possibilidade de atrair turistas, e por consequência emprego e renda (MMA), não há estudos sobre o efeito delas sobre o turismo em locais de beleza cênica, preocupando as comunidades que vivem do turismo ecológico (SIMAS, 2012).

Portanto, é de fundamental importância o estudo do impacto ambiental nas áreas a serem licenciadas, a fim de atuar de forma preventiva. Nota-se, ainda, que a escolha do local é um dos principais fatores para minimizar os possíveis impactos sobre o meio.

\section{Paisagem}

A paisagem, no contexto geográfico, é uma categoria de análise espacial relacionada à dinâmica do tempo. Ela representa um conjunto que é compreendido pela combinação de elementos físicos, biológicos e sociais, que interagem e evoluem de forma indissociável. No entanto, ela pode ser entendida e trabalhada a partir de diversas concepções, de acordo com a proposta e a metodologia escolhida.

A cultura se expressa na paisagem por meio das marcas que ela carrega, produzidas pelas atividades humanas. Representa as técnicas que a sociedade domina de acordo com as convicções religiosas, ideológicas e gosto estético dos grupos humanos. Portanto, a paisagem é o instrumento pelo qual se viabiliza a sua compreensão (CLAVAL, 2007).

Contudo, tanto a cultura quanto as atividades humanas não são estáticas, o que permite dizer que elas, também, possuem uma dimensão histórica e temporal. Nesse sentido, Cosgrove (1998) diz que a paisagem, produto da apropriação e transformação do meio pelo homem, possui significados simbólicos que não são afirmações estáticas, formais. Portanto, os valores culturais que elas celebram precisam ser ativamente reproduzidos para continuar a ter significado.

Tendo em vista que as relações do indivíduo com o espaço fazem parte dos primeiros aprendizados culturais e não cessam de se desenvolver, Claval (2007) aponta dois mecanismos básicos nesse processo, que são procedimentos indispensáveis a todos: reconhecer-se, enquanto memorizar imagens concretas, apreensões visuais (às vezes odores ou barulhos) que permitem saber se já se esteve em tal ou qual lugar, e orientar-se, ou seja, situar-se em relação aos lugares num espaço de referência mais amplo e abstrato.

Esses referenciais, também, vão se manifestar na tomada de decisão dos indivíduos, visto que eles são condicionados pelos valores disponíveis em sua cultura, ou seja, são referências ideológicas que estão presentes na forma de crenças, valores, pressuposições, atitudes e sensibilidades. A partir dessas referências, o indivíduo justifica ou guia suas condutas, especialmente diante de situações particulares (BERDOULAY, 2012).

Berque (1998), por meio do conceito Paisagem-Marca e Paisagem-Matriz, conseguiu sintetizar a complexidade que envolve a paisagem enquanto manifestação concreta que está em constante transformação, por causa das lógicas sociais, culturais e simbólicas:

A paisagem é uma marca, pois expressa uma civilização, mas também uma matriz porque participa dos esquemas de percepção, de concepção e de ação - ou seja, da cultura - que canalizam, em certo sentido, a relação de 
uma sociedade com o espaço e com a natureza e, portanto, a paisagem do seu ecúmeno. E assim, sucessivamente, por infinitos laços de co-determinação (BERQUE, 1998, p. 85).

A paisagem enquanto marca é objetiva e material, a paisagem matriz diz respeito a um nível de percepção subjetiva, sendo individual e coletiva. Para Berque (1998, p. 86) "a paisagem é plurimodal (passiva - ativa - potencial) como é plurimodal o sujeito para o qual a paisagem existe; (...) a paisagem e o sujeito são co-integrados em um conjunto unitário, que se autoproduz e se auto-reproduz". Nesse sentido, Corrêa (2012, p. 135) afirma que a paisagem tem papel duplo, pois "se as formas simbólicas refletem os significados estabelecidos, elas também criam significados".

Em razão dessa relação dual, a análise da paisagem não deve se restringir apenas ao aspecto visual, de caráter morfológico, tampouco apenas aos aspectos psicológicos. A paisagem possui especificidades na forma de ser observada, por meio da sua subjetividade, mas ela é objetiva no que se refere aos aspectos concretos. Portanto, a paisagem se dá pela integração do sujeito com o objeto (BERQUE, 1994 apud MELO, 2005).

Com relação à interação do sujeito com o objeto, pode-se dizer que a matriz cultural na qual o indivíduo está inserido é o aspecto maior da subjetividade na sua percepção. Contudo, essa subjetividade não exclui a percepção individual, visto que mesmo inseridas num mesmo contexto, as pessoas possuem experiências distintas a partir das quais elas também estão condicionadas.

\section{Metodologia de Estudo da Paisagem}

A construção da metodologia de estudo foi feita a partir da proposta primeira do trabalho, ou seja, verificar a percepção sobre empreendimentos de energia eólica no município de Tapes/RS. Com essa premissa, escolheu-se que o mais adequado para o estudo é a opção que trabalha a abordagem perceptiva. Assim, responde a essa concepção o referencial teórico-metodológico da Paisagem Marca e Paisagem Matriz (BERQUE, 1998).

Levou-se em conta, também, as considerações do Ministério de Minas e Energia e da Empresa de Pesquisas Energéticas - MME/EPE (2007), no sentido de avaliar o impacto na paisagem, os quais salientam a importância de analisar o impacto visual à distância, relativamente à maior frequência e ao número de observadores. Segundo essas instituições, uma das formas de se obter um diagnóstico genérico é projetar as turbinas nos ambientes, visto que as pessoas podem dimensionar os efeitos provocados pelo parque.

Quanto aos procedimentos metodológicos, utilizou-se como instrumento de pesquisa o questionário aberto para o estudo da paisagem, que tem por princípio a abordagem de questões sem uma preconcepção ou pré-enquadramento das possíveis respostas. Esse processo permite ao entrevistado maior liberdade ao emitir a sua opinião.

Para a análise dos dados, a pesquisa segue o método misto. Essa abordagem de investigação, segundo Creswell (2010) combina ou associa as formas qualitativa e quantitativa, sendo mais do que a simples reunião das duas abordagens em conjunto, de modo que a força geral do estudo seja maior do que a pesquisa qualitativa 
Bier, L. L. e Verdum, R.

ou quantitativa isolada. Isso significa que o estudo pode privilegiar uma forma em relação à outra em determinados momentos do estudo, com vistas a adquirir maior poder explicativo.

A coleta de dados primários foi realizada por meio de instrumento de pesquisa no município de Tapes. Contudo, verificou-se também a necessidade de se realizar, em menor número, a coleta no município de Arambaré, visto que há possibilidade de visualização de um empreendimento com essas dimensões na área rural desse município.

As entrevistas foram realizadas durante seis dias (três dias em abril de 2011 e os outros três em março de 2012). Para a escolha dos atores da paisagem, adotou-se como critério a população socialmente referenciada. Foram identificadas em campo as seguintes categorias: produtores rurais, pescadores, velejadores, turistas, moradores e representantes de instituições públicas e privadas. A amostra é composta por 55 indivíduos que estão distribuídos em diferentes escolaridades, faixas de renda e nível de escolaridade.

Para o estudo da percepção da paisagem na instalação de aerogeradores no município de Tapes, buscou-se compreender, num primeiro momento, a concepção das pessoas entrevistadas sobre a paisagem e os seus elementos constituintes, associados às suas formas e funções. Dentro dessa estrutura, também se tentou apreender como os entrevistados entendem e visualizam a evolução da paisagem, de um tempo passado ao presente e suas projeções de visão para uma paisagem do futuro, com a presença dos aerogeradores.

\section{Resultados}

Tapes possui extensão territorial de $804,1 \mathrm{~km}^{2}$ e fica a aproximadamente $102 \mathrm{~km}$ de Porto Alegre, capital do estado. O município encontra-se na Unidade Geomorfológica da Planície Costeira do Rio Grande do Sul (Figura 1), mais precisamente na porção interna, que tem sua formação nos processos de regressão e transgressão da marinha do Quaternário. Como características dessa área, encontram-se as terras baixas, com presença de feições colinosas, terraços, planícies arenosas, fluviolacustres, campos de dunas e praias (SUERTEGARAY e MOURA, 2012).

Devido às características físicas, principalmente morfopedológicas, e o contexto histórico de ocupação do município, a população está concentrada na parte leste do município, próximo à Laguna dos Patos, onde o relevo é mais suave.

De acordo com o Censo Demográfico de 2010 (IBGE), o contingente populacional é da ordem de 16.649 habitantes. Nos anos 2000, Tapes contabilizava cerca de 16.291 habitantes, o que significa que houve um pequeno aumento da população. No entanto, em dez anos, houve uma diminuição da população da área rural. A população da área urbana, no período 2000 a 2010, passou de $85,18 \%$ para $87,06 \%$, enquanto a área rural de $14,82 \%$ para $12,94 \%$ do total da população. 


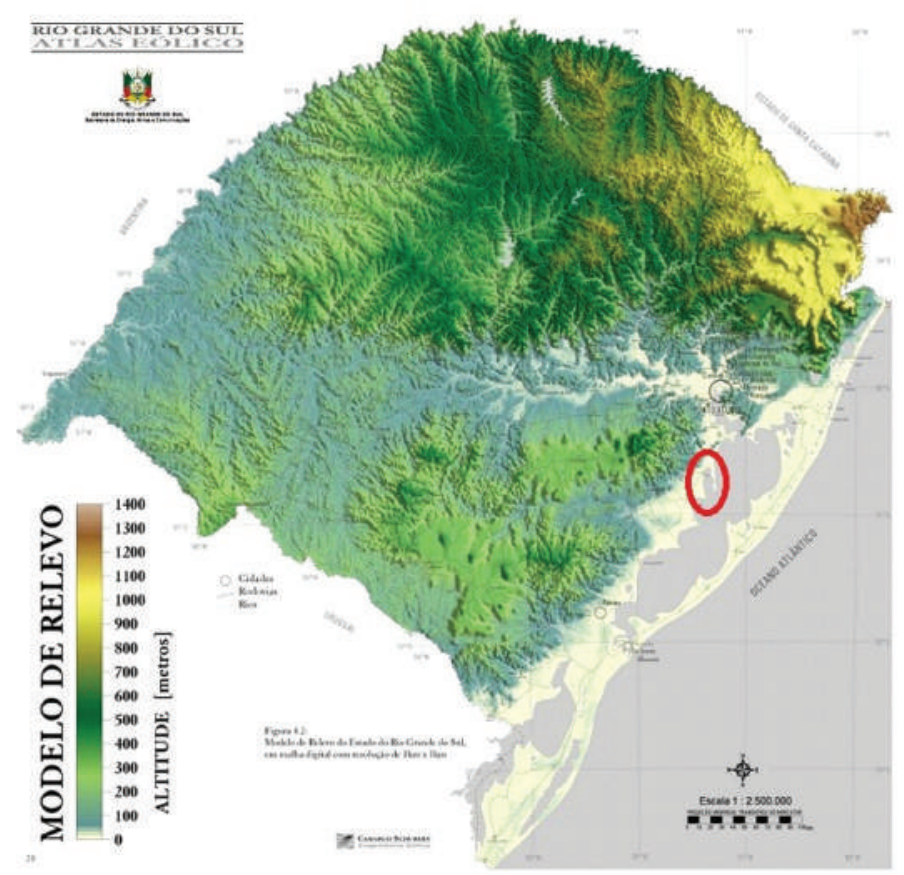

Figura 1 - Localização do município de Tapes/RS. Modificado de: SEMC-RS (2002).

No Índice de Desenvolvimento Humano Municipal (IDHM), Tapes ocupa a 2059å posição, em 2010, em relação aos 5.565 municípios do Brasil. Em relação ao estado do Rio Grande do Sul, entre os 496 municípios, Tapes ocupa a 332a posição, sendo que 331 (66,73\%) municípios estão em situação melhor e 165 (33,27\%) estão em situação pior ou igual (PNUD, 2013).

O IDHM de Tapes é 0,695, em 2010, o que remete a um Desenvolvimento Humano Médio (IDHM entre 0,6 e 0,699). Entre 2000 e 2010, a dimensão que mais cresceu em termos absolutos foi a educação (com crescimento de 0,109 ), seguida pela longevidade e pela renda (PNUD, 2013).

Quanto à estrutura fundiária, a de Tapes está diretamente relacionada com as atividades de arroz irrigado e pecuária de corte, que são consideradas tradicionais no município e que, ainda, moldam a paisagem rural. A atividade de pecuária extensiva remonta à ocupação do território pelos portugueses no século XVIII, e o cultivo do arroz nas áreas de planície às primeiras décadas do século XX. Estima-se que em 2006, entre 61 e 87\% das propriedades possuam mais de 500 ha (IBGE), o que significa a alta concentração de terras.

Grande parte da paisagem do município corresponde às lavouras temporárias de arroz, e, mais recentemente, de soja. Na lavoura permanente, destaca-se o pomar de pêssego. Na pecuária, o principal rebanho é o de bovinos, seguido de galos, frangos, frangas e pintos. Entre os produtos da agropecuária, Tapes produz, principalmente, leite de vaca, ovos de galinha, mel de abelha e lã (IBGE).

O Produto Interno Bruto do município deve-se, sobretudo, ao setor terciário (IBGE), que além das atividades de prestação de serviços comum às demandas da cidade, tem 
Bier, L. L. e Verdum, R.

o complemento das atividades turísticas, visto que Tapes possui praias de água doce, da Laguna dos Patos, e este atrativo é um importante instrumento na política local.

\section{Paisagem Perceptiva}

Em uma primeira abordagem, que visa identificar o que forma o conjunto da paisagem, podem-se separar as respostas em três grupos distintos:

No primeiro grupo, as respostas são muito semelhantes, com enfoque na amplitude da visão frente à paisagem. Entre as respostas, destacam-se como representativas: "o conjunto do entorno", "a vista", "o que se enxerga", "o horizonte", entre outros.

No segundo grupo, são citados os elementos da natureza como componentes principais da paisagem, como: "campos, árvores e lagoa", "natureza, verde, campo e água", "árvore, montanha, água e flora" etc. No entanto, algumas pessoas citam as "lavouras", ou seja, a natureza transformada pelas atividades agrícolas.

O terceiro e menor grupo engloba respostas diversificadas e acuradas sobre a paisagem. Aqui entram percepções que abrangem os compartimentos da paisagem (as planícies, os vales, as coxilhas, os morros, a serra), suas transformações ao longo do tempo e os elementos construídos. Fazem parte das citações: "a composição do relevo", "conjunto de coisas que se transformam" e "a composição da lagoa, do campo e da cidade". Também aparecem respostas subjetivas, como: "a paisagem é abstrata e pessoal".

A principal Paisagem Marca - no contexto da percepção, ou seja, que sinaliza as preferências pela familiaridade, assim como os aspectos históricos, culturais e de lazer é a Laguna dos Patos, popularmente chamada de Lagoa dos Patos, sendo a referência na região para a grande maioria dos entrevistados (85,4\% das citações) (Figura 2).

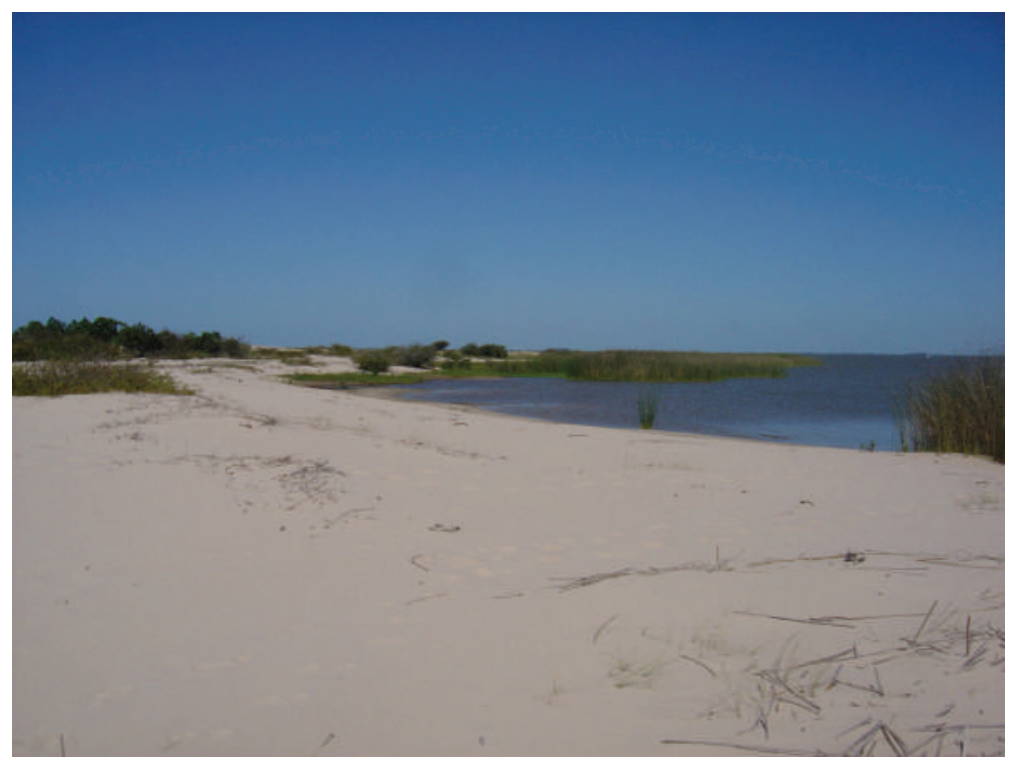

Figura 2 - Laguna dos Patos/Saco de Tapes, Pontal de Tapes. Foto: Roberto Verdum, 20/03/2011. 
Outras paisagens também foram citadas como referências e caracterizam aspectos de identidade frente às paisagens no município, embora com menor expressividade. Aqui se destacam as paisagens rurais (com 18,2\% das citações - Figura 3), seguidas das matas nativas (10,9\% do total - Figura 4). O conjunto dos elementos que compõem a paisagem e que representam os compartimentos da paisagem foi indicado por quatro pessoas $(7,3 \%)$.

A preferência por essas paisagens deve-se a diferentes fatores, basicamente relacionados aos elementos atrativos e aos aspectos subjetivos. Dessa forma, no primeiro grupo consideram-se citações como: "relação com a natureza", "lugar bonito", "construção da natureza", "preservação", "ar puro", assim como "praia", "mata nativa", "dunas", "butiazais", "pesca" e "esportes". No segundo grupo, que é composto por elementos subjetivos, as citações aparecem em menor escala. Destacam-se os seguintes elementos: "lembrança da infância" e "cheiro" de determinado local.

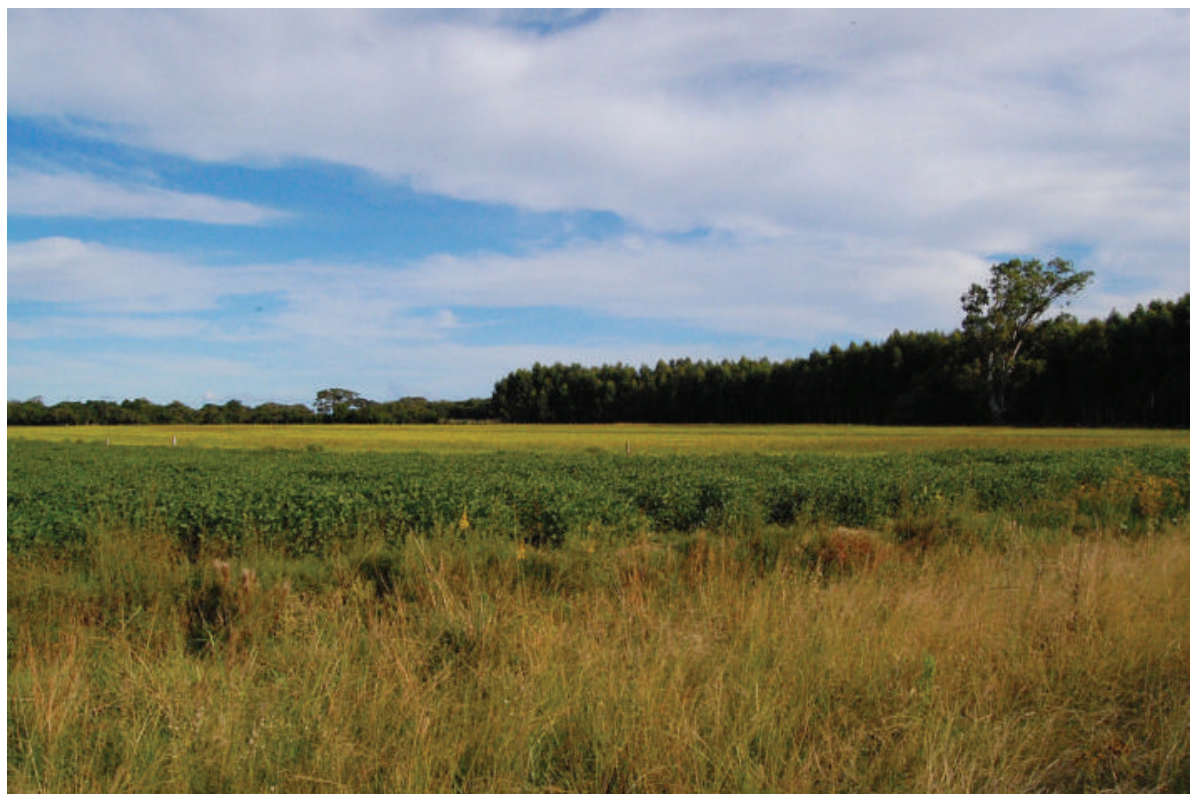

Figura 3 - Paisagem rural: composição de sistemas de cultivos diversos/Porção Norte Tapes/RS. Foto: Roberto Verdum, 25/03/2012. 


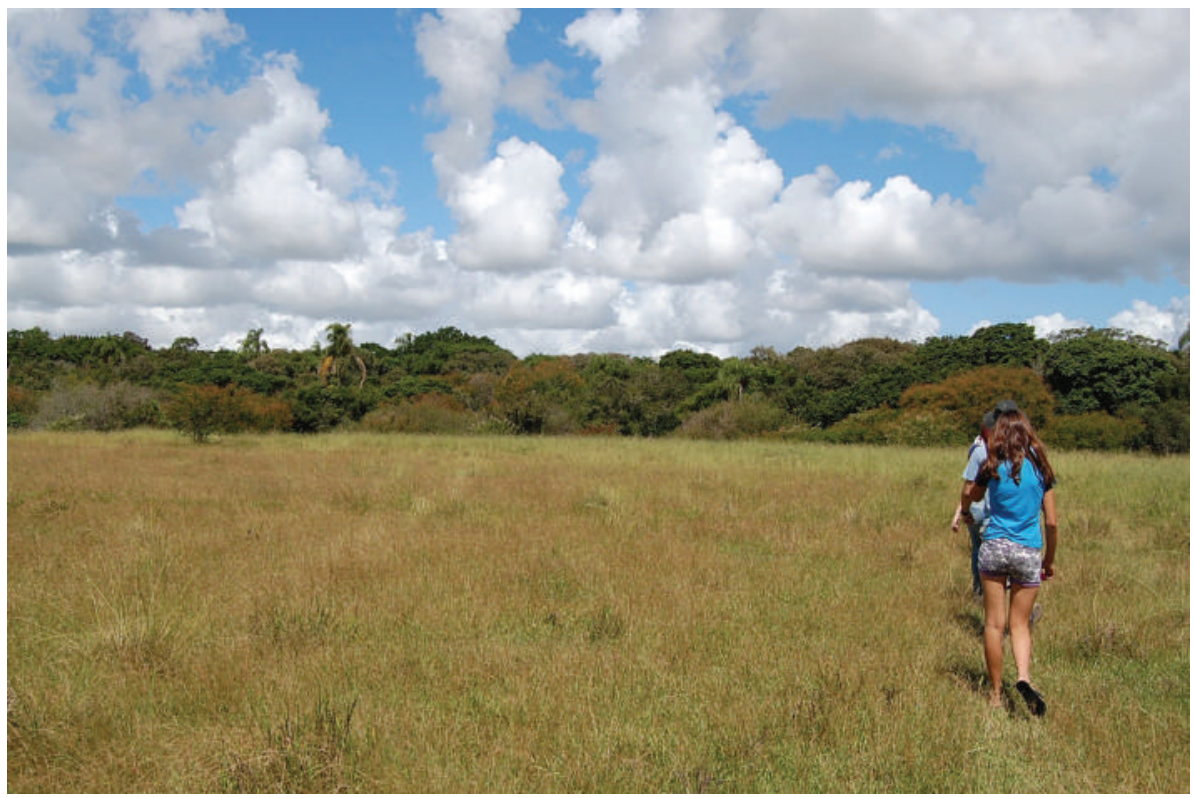

Figura 4 - Paisagem rural: mata ciliar junto à rede de drenagem, arroio das Capivaras/ Porção Sul - Tapes/RS. Foto: Roberto Verdum, 24/03/2012.

Em relação aos aspectos marcantes das paisagens identificados, as respostas foram separadas em três categorias:

- Uso - quando o aspecto marcante está relacionado com as atividades esportivas, de lazer e como meio de reprodução social. Agrupam citações como "acampar", "descanso", "praia", "banho", "terra agrícola", "esporte", "pesca" etc.

- Adjetivação - englobam características positivas, como: "ambiente lindo", "renovação", "qualidade de vida", "topografia plana", "visual", "pôr do sol", "beleza natural", "tranquilidade" etc.

- Valor histórico - fazem parte da história individual ou coletiva, como: "economia", "lembrança da navegação", "memória", "acontecimentos históricos", entre outros.

Partindo-se para outro nível de percepção das paisagens, elas foram classificadas pelos entrevistados segundo o grau de satisfação que elas proporcionam a eles, em uma escala de 1 a 5 (diretamente proporcional ao grau de satisfação). As Paisagens de Referência trazem um grau de satisfação bastante elevado, concentrando os resultados nas valorações 4 e 5. Entretanto, alguns valores menores são atribuídos a essas paisagens, por causa do reconhecimento de que já foram mais bem cuidadas ou por terem um potencial não explorado adequadamente.

Nesse contexto, entram argumentos como: "as áreas degradadas", "a má condição da infraestrutura", "a falta de conservação", "a poluição", "a ocupação desordenada", "as ressacas que destroem elementos na praia", "o esgoto", "a má qualidade da água" e 
"o lixo". Também, há citações sobre as paisagens dos cultivos de arroz, que poderiam ser mais diversas, assim como a situação dos engenhos, que se encontram, em sua maioria, abandonados.

\section{Transformação da Paisagem - Tempo Passado, Presente e Futuro}

Em relação às paisagens identificadas pelos entrevistados, as principais atividades reconhecidas do tempo passado estão ligadas aos ciclos econômicos desenvolvidos no meio rural e na laguna. A produção de arroz $(59 \%)$, a pecuária $(38,5 \%)$, a pesca $(38,55)$ e a atividade portuária (33,3\%) são as atividades mais citadas, sendo que dessas, a orizicultura é a única em que a maioria das pessoas a identifica como uma alteração negativa sobre a paisagem $(23,1 \%)$. Isso se explica pela identificação de um conflito de uso: a laguna enquanto recurso para irrigação de arroz e a degradação que essa atividade gera, alterando as condições de balneabilidade e da qualidade na atividade pesqueira. Entretanto, o grau de satisfação com a paisagem da produção de arroz (20,5\%), também é notório, o que se atribui à funcionalidade da paisagem no que diz respeito à economia do município.

A silvicultura - pinus e eucalipto (citada por 12,8\%), também é vista como um elemento de impacto negativo na paisagem (10,3\%), inclusive pelas alterações que ocorreram nos campos de dunas no Pontal e nas margens da Laguna.

Em relação às atividades desenvolvidas atualmente, nota-se que a produção de arroz, principal atividade econômica do município, é a mais citada $(74,4 \%)$. No entanto, verificou-se que além das alterações citadas anteriormente, a mecanização agrícola é vista como uma alteração recente nas lavouras. Para alguns, essa modificação é negativa $(33,3 \%)$, por ser um fator de exclusão social, e para outros significa modernização do campo $(23,1 \%)$.

A retomada da pecuária foi a segunda atividade mais citada $(46,2 \%)$, gerando certo grau de satisfação em relação à alteração que gera na paisagem $(15,4 \%)$. Já o turismo $(30,8 \%)$ e a prática de esportes $(25,6 \%)$, também foram citados e, em conjunto com a pesca $(35,9 \%)$, receberam as melhores avaliações quanto às modificações da paisagem $(10,3 \%, 15,4 \%$ e $10,3 \%$, respectivamente).

\section{Empreendimento de Energia Eólica}

A projeção de um empreendimento eólico em Tapes remete a uma paisagem futura. Contudo, há o conhecimento na região sobre essa possibilidade vir a se concretizar. Dessa forma, a maior parte dos entrevistados (80\%) tem conhecimento de que há projetos de energia eólica para o município, visto que tem sido amplamente divulgado nos meios de comunicação local, embora não saibam exatamente a localização dos empreendimentos.

Entretanto, verificou-se que a dimensão dos aerogeradores é desconhecida ou até subestimada por mais da metade dos entrevistados (63,6\%).

A opinião dos entrevistados em relação a esse tipo de empreendimento é amplamente favorável $(92,7 \%)$, devido aos benefícios diretos ao município, como tributos que possibilitarão o desenvolvimento econômico e social. Outro benefício direto citado é o 
Bier, L. L. e Verdum, R.

ganho com o arrendamento de terras, embora seja mais restrito ao proprietário da terra. Há, também, a expectativa de que a população local tenha oportunidade de empregos, sendo a sua falta um dos fatores da saída dos jovens da cidade para outras localidades mais atrativas economicamente.

Entre os benefícios indiretos, são citados: a possibilidade de exploração do turismo, o ganho em educação e cultura, a geração de energia limpa, a qualidade de vida e as melhorias na infraestrutura da cidade. Outra questão levantada e motivo de discordância entre os entrevistados é a aviação agrícola. Algumas pessoas consideram que com a instalação de aerogeradores, o uso dos agrotóxicos irá diminuir no campo, entretanto, outros veem essa possibilidade como um problema em relação às atividades agrícolas desenvolvidas atualmente.

Sobre os possíveis impactos negativos relacionados à instalação dos aerogeradores, predomina a preocupação quanto à origem da mão de obra que será utilizada, podendo ela gerar uma tensão social na comunidade local.

Em relação ao impacto na paisagem, decorrente da instalação dos aerogeradores, para $89,1 \%$ dos entrevistados, esses equipamentos possuem influência na paisagem, mas de caráter positivo. Entretanto, uma pequena parcela ressalta que a questão visual depende de como as turbinas serão distribuídas na paisagem. Verificou-se que há pessoas que se satisfazem com a paisagem projetada por acharem que é uma opção menos prejudicial em relação a outros possíveis empreendimentos. Entre as opiniões, destacam-se: "enobrece a paisagem", "bonito", "imponente", "moderno" e "progresso". Também, há uma parcela que considera uma intervenção, um elemento não natural, embora não agressivo, enquanto alguns mantêm uma preocupação com a paisagem em longo prazo.

Para 41,8\% dos entrevistados, existirá influência do empreendimento de energia eólica nas atividades desenvolvidas no município, sobretudo, por meio de novas funcionalidades que o projeto poderá trazer para a região (turismo, serviços e economia) e a compatibilidade com as atividades desenvolvidas no campo. Para a possível interferência negativa, estão os transtornos na época de obras, o ruído, a redução da área de plantio e a possível interferência que os equipamentos podem causar no gado.

As paisagens restritivas para o empreendimento, segundo a opinião dos entrevistados, são as de uso comum. O balneário, as proximidades da área urbana e as áreas de preservação ambiental foram as mais vetadas para a instalação dos aerogeradores. Já a área preferencial é a rural, devido a sua amplitude, ao distanciamento da população ou por já existir uma atividade que pode ser complementar, como as áreas de lavoura e pecuária. Apenas 12,7\% restringem a presença dos aerogeradores nas paisagens de referência.

Por último, sobre os possíveis impactos ambientais nas fases de instalação e operação dos aerogeradores, identificou-se a preocupação quanto às aves migratórias, ao ruído, aos resíduos das obras, ao desmatamento, ao acesso ao empreendimento e à distância deles da população. Também, foram citadas como observações a serem consideradas nessas fases, a preferência por instalações de cabos subterrâneos e a necessidade de estudos que possam inferir sobre os cuidados necessários à segurança da população e ao meio ambiente. 


\section{Considerações Finais}

A paisagem permite diversas abordagens para o estudo da geografia, e a escolha da metodologia perceptiva, por meio da Paisagem Marca e Matriz, mostrou-se muito oportuna aos objetivos propostos pelo estudo. Os dados obtidos foram de riquíssimo valor, com os quais fora permitido uma aproximação com a população local, sobretudo com agentes locais que funcionam como difusores de ideias e lógicas que são elaboradas na perspectiva das suas concretizações. Não se teve, apenas, uma coleta, quantificação e estruturação dos dados. O método permitiu o entendimento dos processos que norteiam a opinião da população frente à possibilidade de implantação de um empreendimento de energia eólica.

A primeira abordagem sobre a concepção da paisagem fez com que os resultados ficassem mais claros em relação à opinião e ao empreendimento. Dessa forma, pode-se afirmar que o entendimento das pessoas em relação à paisagem está, sobretudo, relacionado aos elementos naturais. No entanto, em relação à dinâmica temporal, os processos atuantes que modelam essa paisagem são vistos por meio dos ciclos econômicos do município.

Mesmo que a população local não tenha vivenciado a experiência direta com um empreendimento eólico concreto, notou-se que este traz um conjunto de expectativas. Ou seja, pode-se dizer que, embora o empreendimento seja relativo às técnicas para geração de energia, ele também introduz diversas significações que lhe são atribuídas.

Um parque eólico é visto como uma possibilidade de desenvolvimento para a região, principalmente socioeconômico. Em tempos de maior consciência ambiental, por ser uma fonte de energia que não emite poluentes durante a sua operação, as usinas eólicas têm um forte apelo. Além disso, é um elemento novo nas paisagens do estado do Rio Grande do Sul, que está, também, relacionado com a inovação tecnológica.

Se analisarmos pela objetivação dos aerogeradores na paisagem, as estruturas em si, a ampla maioria reconhece que há uma modificação nela. Contudo, essas estruturas geram certo conforto, exatamente por todos esses elementos tecnológicos e socioeconômicos aos quais elas estão associadas.

Nesse sentido, fica clara a relação da Paisagem Marca e Matriz, objetiva e subjetiva, enquanto indissociáveis. Olhando-se os dados, observa-se que a aceitação desse empreendimento é quase que total por parte dos entrevistados, por causa dos possíveis benefícios que estão incutidos no imaginário local. Todavia, analisando apenas a opinião sobre o impacto na paisagem, nota-se que o percentual de atratividade é menor do que do empreendimento em si. Isto significa que não é o aerogerador, enquanto estrutura física, que gera tamanha excitação, mas as expectativas de melhorias que ele possibilita ou projeta.

Mesmo que seja considerada uma intervenção positiva, as pessoas preferem manter certa distância desses equipamentos. Os locais de uso comum são os mais restritivos, enquanto a área rural é a preferencial, pois não há o contato direto com os equipamentos.

Também, é necessário salientar que se tratou de uma hipótese de instalação na área rural do município, que já possui alterações bastante significativas, em especial pelo cultivo do arroz consorciado com a atividade de pecuária extensiva. Conforme mostrado nos resultados do estudo, essa já é uma modificação que traz críticas de boa parte da população. A plantação de pinus no município, por exemplo, causou degradação ambiental, em especial na área de dunas, e, logo, não é bem-vista. 
Bier, L. L. e Verdum, R.

Conclui-se, por fim, que o estudo permite o entendimento das pessoas em relação a um empreendimento de energia eólica. Entretanto, por se tratar de um elemento novo no estado, as pessoas não possuem maiores informações sobre o real impacto, positivo e negativo, que pode ser gerado. A partir desses novos empreendimentos que estão sendo instalados, o acesso à informação e o desenvolvimento de novos estudos deverão aumentar, o que pode ajudar a formar uma opinião crítica por parte da população e dos gestores públicos e privados.

\section{Referências Bibliográficas}

ANEEL - AGÊNCIA NACIONAL DE ENERGIA ELÉTRICA. Banco de Informações de Geração. Disponível em:

<http://www.aneel.gov.br/aplicacoes/capacidadebrasil/OperacaoGeracaoTipo.asp?tipo= 7\&ger=Outros\&principal=E\%C3\%B3lica $>$. Acesso: 18 maio. 2014.

Atlas de energia elétrica do Brasil. Brasília: ANEEL, 3ª ed., 2008.

Atlas de energia elétrica do Brasil. Brasília: ANEEL, 2ª ed., 2005.

BAITELO, R. Energias renováveis: eólica e solar. In: MOREIRA, P.F.; MILLIKAN, B. (orgs). O setor elétrico brasileiro e a sustentabilidade no século 21: oportunidades e desafios. Brasília: Brasil, 2a ed., p. 71-9. 2012.

BERDOULAY, V. Espaço e cultura. In: CASTRO, I. E. et al. (orgs.). Olhares geográficos: modos de ver e viver o espaço. Rio de Janeiro: Bertrand Brasil., 2012, p. 101-31.

BERQUE, A. Paisagem-Marca, Paisagem-Matriz: elementos da problemática para uma geografia cultural. In: CORRÊA, R. L.; ROSENDAHL, Z. (orgs.). Paisagem, tempo e cultura. Rio de Janeiro: EDUERJ, 1998, p. 84-91.

BIER, L. L. Estudo da paisagem: implantação de aerogeradores em Tapes/RS. Trabalho de Conclusão de Curso. (Graduação em Geografia). Porto Alegre: Universidade Federal do Rio Grande do Sul, 2013.

CE-EÓLICA PUC/RS - CENTRO DE ENERGIA EÓLICA DA PONTIFÍCIA UNIVERSIDADE CATÓLICA/RS. Perguntas frequentes sobre energia eólica. Disponível em: <http://www. pucrs.br/ce-eolica/faq.php?q=1\#1>. Acesso: dez. 2012.

CLAVAL, P. A geografia cultural. Florianópolis: Ed. da UFSC, 3ª ed., 2007.

CORRÊA, R. L. Espaço e simbolismo. In: CASTRO, I. E. et al. (orgs.). Olhares geográficos: modos de ver e viver o espaço. Rio de Janeiro: Bertrand Brasil, 2012, p.133-53.

COSGROVE, D. A geografia está em toda parte: cultura e simbolismo nas paisagens humanas. In: CORRÊA, R. L.; ROSENDAHL, Z. (orgs.). Paisagem, tempo e cultura. Rio de Janeiro: EDUERJ, 1998, p. 92-122. 
CRESWELL, J. W. Projeto de pesquisa: métodos qualitativo, quantitativo e misto. Porto Alegre: Artmed, $3^{\text {a }}$ ed., 2010.

IBGE - INSTITUTO BRASILEIRO DE GEOGRAFIA E ESTATÍSTICA. CIDADES@. Disponível em: <http://www.ibge.gov.br/cidadesat/link.php?uf=rs>. Acesso: dez. 2013.

MELO, V. L. M. O. A paisagem sob a perspectiva das novas abordagens geográficas. In: Encontro dos geógrafos da América Latina, 10, São Paulo. Anais. São Paulo: USP, 2005, p. 9146-65.

MEIRELES, A. J. A. Impactos ambientais em áreas de preservação permanente (APP's) promovido no Campo de Dunas da Taíba pela Usina Eólica Taíba Albatroz - Bons Ventos Geradora de Energia S/A. Parecer Técnico. Fortaleza: UFC, 2008.

MMA - MINISTÉRIO DO MEIO AMBIENTE. Energia eólica. Disponível em: <http://www. mma.gov.br/clima/energia/energias-renovaveis/energia-eolica>. Acesso: dez. 2012.

MME / EPE - MINISTÉRIO DE MINAS E ENERGIA / EMPRESA DE PESQUISAS ENERGÉTICAS. Plano Nacional de Energia 2030. Brasília: MME / EPE, V. 9, 2007. Disponível em: <http://www.mme.gov.br/mme/menu/todas_publicacoes.html>. Acesso: dez. 2012.

PNUD - PROGRAMA DAS NAÇÕES UNIDAS PARA O DESENVOLVIMENTO. Atlas do desenvo/vimento humano no Brasil 2013. Disponível em: <http://www.atlasbrasil.org. br/2013/pt/perfil/tapes_rs>. Acesso: 18 mai. 2014.

SIMAS, M. S. Energia eólica e desenvolvimento sustentável no Brasil: estimativa da geração de empregos por meio de uma matriz insumo-produto ampliada. Dissertação (Mestrado - Programa de Pós-Graduação em Energia). São Paulo: USP, 2012.

SUERTEGARAY, D. M. A.; MOURA, N. S. V. Morfogênese do relevo do estado do Rio Grande do Sul. In: VERDUM et al. (orgs.) Rio Grande do Sul: paisagens e territórios em transformação. Porto Alegre: Editora da UFRGS, 2ae ed., 2012.

Recebido em: 30/5/2014 Aceito em: 25/6/2014

\footnotetext{
1 Jornal Correio do Povo. Disponível em: <http://www.correiodopovo.com.br/Impresso/?Ano=116\& Numero=139\&Caderno=0\&Noticia $=258179>.16$ fev. 2011.

${ }^{2}$ Instituto Curicaca. Disponível em: <http://ong.portoweb.com.br/curicaca/default.php?reg=36\&p_

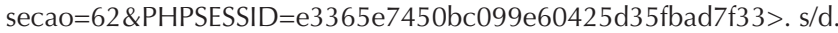

${ }^{3}$ O PROINFA estabeleceu o índice de $60 \%$ de nacionalização dos empreendimentos, objetivando fortalecer a indústria brasileira de energia elétrica. Mais informações na página do programa: $<$ http://www.mme.gov.br/programas/proinfa/>.

4 Disponível em <http://www.epe.gov.br/leiloes/Documents/Leil\%C3\%B5es\%202014/ INFORME\%20\%C3\%80\%20IMPRENSA-5\%202014.pdf>.

${ }^{5}$ Originalmente, a publicação do estudo estava prevista para 2013, conforme Assessoria de Imprensa da FEPAM (Fundação Estadual de Proteção Ambiental Henrique Luiz Roessler - RS. Disponível em $<$ http://www.sema.rs.gov.br/conteudo.asp?cod_menu=4\&cod_conteudo=7986\&busca $=$ atlas $\% 20$ e\%F3lico>. 14 nov. 2012.
} 
